\title{
Metabólitos sanguíneos hormonal e mineral de cabras leiteiras hígidas acompanhadas durante o período de transição
}

Gliére Silmara Leite Soares ${ }^{[]^{*}}$, Rodolfo José Cavalcanti Souto ${ }^{[b]}$, Alexandre Tadeu Mota Macedo ${ }^{[b]}$, Jobson Filipe de Paula Cajueiro $^{[a]}$, Rafael Otaviano do Rêgo $0^{[b]}$, Daniel Nunes de Araujo Gonçalves ${ }^{[[]}$, Jomel Francisco dos Santos ${ }^{[b]}$, Pierre Castro Soares ${ }^{[d]}$, José Augusto Bastos Afonso ${ }^{[e]}$, Carla Lopes de Mendonça ${ }^{[e]}$

\footnotetext{
[a] Programa de Pós-Gradução em Sanidade e Reprodução de Ruminantes, Universidade Federal Rural de Pernambuco (UFRPE), Garanhuns, PE, Brasil

[b] Programa de Pós-Graduação em Ciência Veterinária, Universidade Federal Rural de Pernambuco(UFRPE), Garanhuns, PE, Brasil

[c] Programa de Pós-Graduação em Ciência Animal Tropical, Universidade Federal Rural de Pernambuco (UFRPE), Garanhuns, PE, Brasil

[d] Departamento de Medicina Veterinária, Universidade Federal Rural de Pernambuco (UFRPE), Garanhuns, PE, Brasil

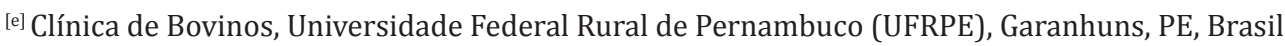

*Autor correspondente

e-mail: glieresilmara@hotmail.com

\section{Resumo}

As cabras leiteiras, assim como as vacas, apresentam marcantes alterações metabólicas no período que corresponde as últimas semanas de gestação e as primeiras de lactação, fase na qual compreende o período de transição, resultando em marcantes alterações hormonais, assim como de alguns minerais, particularmente o cálcio. 0 conhecimento fisiológico da dinâmica sanguínea destes componentes é de fundamental importância para a compreensão da fisiopatogenia de alguns distúrbios metabólicos comumente observados na cabra leiteira, como a toxemia da prenhez e a hipocalcemia. Este trabalho teve por objetivo avaliar o perfil hormonal por meio da determinação sanguínea de cortisol, insulina, T3 livre e T4 livre, bem como os níveis do cálcio iônico e total de cabras leiteiras hígidas. Foram acompanhadas durante o período de transição 94 cabras leiteiras clinicamente saudáveis, mestiças, multíparas, e prenhas, provenientes de propriedades localizadas na região semiárida do estado de Pernambuco. Todas as propriedades adotavam o sistema de criação intensivo, onde os animais eram vacinados e vermifugados sistematicamente e a alimentação era composta por bagaço de cana-de-açúcar, palma e farelo de trigo, milho, soja e algodão, além de sal mineral e água à vontade. Amostras de sangue foram colhidas aos 30 dias antes do parto (30 dap), 20 dap, 10 dap, dia do parto (P), 10 dias após o parto (10dpp), 20 dpp e 30 dpp. 
Para a análise estatística empregou-se a análise de variância ao nível de $5 \%$ de probabilidade avaliando-se o efeito de momento. A insulina apresentou diminuição gradativa dos valores médios no final da gestação, sendo o menor valor médio $(\mathrm{P}<0,05)$ observado no momento do parto $(15,56 \mathrm{pmol} / \mathrm{L})$, estabilizando-se durante a lactação. Este comportamento reflete os mecanismos adaptativos da fêmea sobre o metabolismo energético para suprir o aumento na demanda energética gerado pelo desenvolvimento fetal. 0 cortisol apresentou elevação $(P<0,05)$ no momento do parto, no qual foi registrado a maior concentração $(57,67$ nmol/L), diminuindo durante a lactação; os glicocorticoides funcionam como sinalizadores da hora do parto. Os hormônios tireoidianos T3 e T4 nas suas formas livres não apresentaram variação nas concentrações médias ao longo dos momentos experimentais ( $\mathrm{P}>0,05)$, apresentando média geral de 5,19 pmol/L e $6,80 \mathrm{pmol} / \mathrm{L}$, respectivamente. Quanto ao cálcio iônico, considerado a forma mais importante, sob o ponto de vista biológico, não foi verificado variação ao longo dos momentos, não sendo verificado o mesmo na concentração do cálcio total, que apresentou valores inferiores aos demais no momento do parto $(1,77$ mmol/L), provavelmente por sofrer influência da concentração proteica, ratificando a necessidade de se mensurar o cálcio iônico. 0 conhecimento das adaptações fisiológicas hormonais e minerais da cabra leiteira durante este período permite identificar precocemente qualquer alteração decorrente dos distúrbios metabólicos, aos quais são vulneráveis neste período. 